\title{
Microcontroller-based RFID, GSM and GPS for Motorcycle Security System
}

\author{
Kunnu Purwanto ${ }^{1}$ Iswanto $^{2}$, Tony Khristanto Hariadi ${ }^{3}$, Muhammad Yusvin Muhtar ${ }^{4}$ \\ Department of Electrical Engineering, \\ Universitas Muhammadiyah Yogyakarta, \\ Yogyakarta, Indonesia
}

\begin{abstract}
The crime level including motorcycle theft has been increasing. It occurs regardless the time and place. The owner of the motorcycle needs to ensure the security of his motorcycle by adding either manual or electronic lock. However, both the manual and electronic locks are still incapable to protect the motorcycle from the theft. Based on the problem, this research created an automatic motorcycle safety system, namely, germs narcissistic. Germs narcissist is the key innovation of automatic vehicle security using, GPS (global positioning system), and GSM (global system for mobile communication), and RFID (Radio Frequency Identification). This system was created by using short message service (SMS) to provide vehicle information such as time, position, and alarm informed to the owner of the motorcycle. The arrangement of the technologies can be used as a practical and effective safety key of motorcycle.
\end{abstract}

\section{Keywords-Microcontroller; GPS; GSM; RFID; motorcycle}

\section{INTRODUCTION}

A rampant motorcycle theft proves that the hospital's motorcycle security system is poor. The need for an additional security system is considered very necessary to avoid the theft. Such conditions require vehicle owners to pay more attention to the vehicle safety so that a good security system is needed.

Supporting the description of the case, many simple or advanced security tools for motorcycle have been developed. Several manufacturers have already provided such security systems such as keys to the motorcycle handle bar and alarm systems for four-wheel vehicles. However, the security systems provided by the manufacturers are less assuring in the recent modern era. There should be an additional security. Nasir \& Mansor [1] developed security systems of two-wheeled vehicles with the use of technology. They created an automatic key for a two-wheeled vehicle by using a microcontroller. A security system for four-wheeled vehicles using wireless sensor network technology has been developed by Tang et al. [2] and Sehgal et al. [3] succeeded in developing a security system using SMS to track missing motor vehicles.

In this study, a Very Important Person (VIP) [4] model of security system is implemented. To outline, a VIP security model consists of several layers namely the first, the second, the third secure points and so forth. Two layers of security were applied. The first is Authentication method and the second is Point Positioning.

The authentication method is widely applied to many computer security systems whereas the Point Positioning method is used in global positioning system. Rui Chen [5] applied authentication method for wireless network security system. Hameed et al. [6] used Point Positioning method to compare the accuracy of the data processing of global positioning system -online from some global positioning system data Processing services.

Basically, the principle of Authentication method is a method to access certain systems such as password [7], fingerprint, eye retina [8], face recognition [9], ID number (unique number) [10] and others. The study used the introduction of the ID number. By using RFID technology, there will be no duplication or same ID numbers.

A Point Positioning [11]-[13] method or also called an absolute method is the basic method in global positioning system which aims to obtain a position in real-time with good accuracy [14]-[16]. In the security system, a standard security system by applying the Authentication method is used as the first secure point. The motorcycle rider should first introduce his ID number to turn on the motor vehicle. The Global Positioning System (GPS) for tracking systems position by applying Point Positioning method [17]-[19] was used as the second secure point.

All systems are regulated by a single component, namely Microcontroller [12], [20], [21]. The controller of the systems is Radio Frequency Identification (RFID). By implementing the Authentication method, the security of the motorcycle is significantly improved because the rider must enter his ID number to unlock the handle bar and turn the engine on. By using Point Positioning method, the position can be identified in real-time with good accuracy. In addition, by applying the methods, the motorcycle owner can track the motorcycle position and turn the engine off when it is stolen.

The design of the security system places Arduino as the main controller in which there is a short message alert feature that provides information about the location of the motorcycle. The system is expected to be an innovative motorcycles security system.

\section{RESEARCH METHOD}

The design of double security system based on RFID would be applied to the motorcycle model that has a large trunk. The double security system is based on RFID as shown in Fig. 1. The system consists of two inputs, namely RFID and global positioning system sensors. The inputs are processed using a 
microcontroller. The outputs are LED and LCD indicators. In addition, the system is also connected with a relay to turn off and turn on the engine. The Global System Mobile communication system is used by the system to contact vehicle owners. It is an open-loop control system. The control system refers to the detection output results provided by the Radiofrequency identification detection system. No feedback is provided for the correction process.

The interactive double security system for motorcycle based on RFID consists of several subsystems namely identification, detection, controllers, and output subsystems.

1) Identification subsystem: The identification subsystem conducts input identification. The RFID detection subsystem consists of RFID tag, RFID Reader and Microcontroller Arduino nodemcu as the main controller as shown in Fig. 2. The RFID tag issues data by using the Wi-Fi signal, and then the data are read by a Wi-Fi receiver using an RFID reader. The output of RFID reader data is read by the microcontroller using serial communication.

The figure shows that the RFID Reader reads the RFID identification data, and then send the RFID information to the Arduino nodemcu microcontroller.

2) Detection subsystem: Global positioning system detection subsystem consists of satellites, global positioning system Receiver and the Microcontroller Arduino nodemcu as the main controller [22]. It can be seen in Fig. 3 that the data from the satellite are received by the global positioning system receiver, then the global positioning system data are sent to the Arduino microcontroller to be processed into a longitude and latitude positions.

The satellite detects the presence of the global positioning system receiver and transmits the data in NMEA and GGA formats as information. The data are then sent to Microcontroller Arduino Nodemcu.

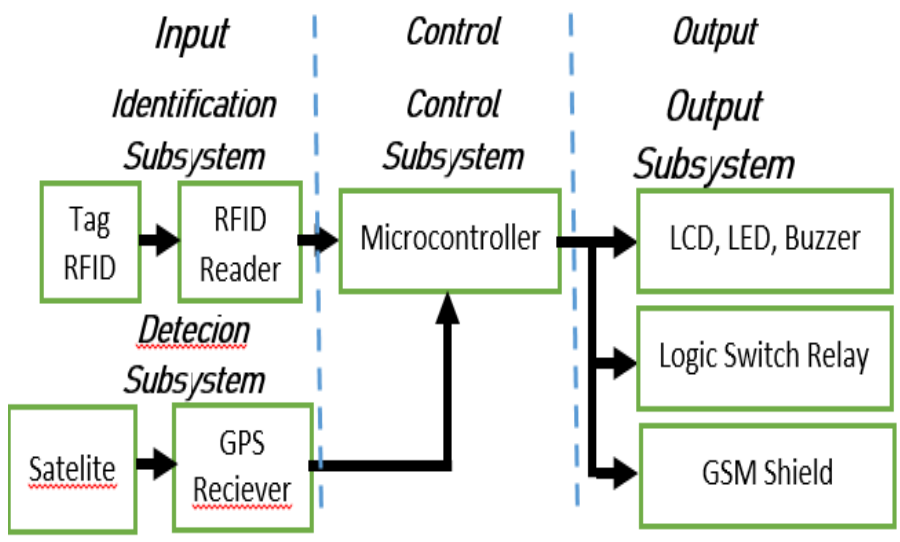

Fig. 1. Block Diagram of the Overall System.

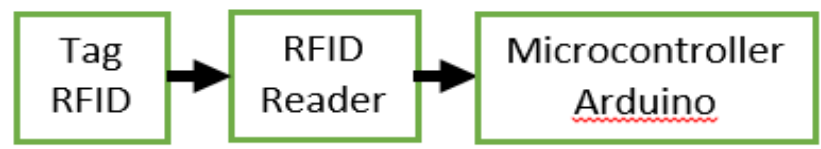

Fig. 2. Block Diagram of RFID Identification Subsystem.

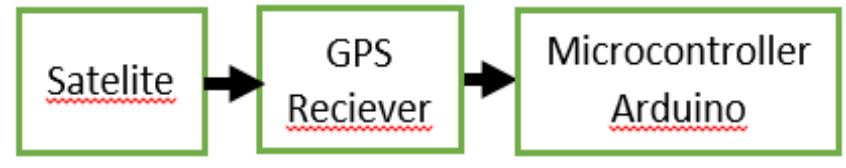

Fig. 3. The Block Diagram of GPS Detection Subsystem.

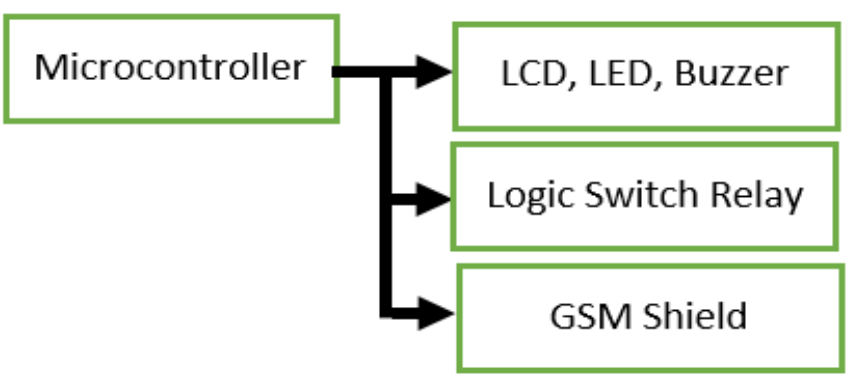

Fig. 4. The Block Diagram of GPS Detection Subsystem.

3) Output subsystem: Fig. 4 shows an output microcontroller consisting of Minimum Output [20], Relay Action [21] and Global System Mobile Communication subsystem. Lamp and alarm are mounted in the microcontroller output subsystem as indicators which indicate the input and a $16 \times 2$ LCD which indicates the data viewer output [22]. An action subsystem is a subsystem that serves as an ignition circuit connecting the twowheel motor vehicles. It can be realized by using a Relay as the automatic switch.

Arduino Nodemcu microcontroller is capable at providing a high condition voltage of 5 volts initial output as a trigger to activate the relay so that the motor circuit ignition systems is possible to be connected to the vehicle key switch so that the ignition system will only be activated when the ignition relay and the circumstances are connected. A Global System Mobile communication subsystem serves as a tool that supports communication between the microcontroller and the vehicle owner's mobile phone. The Linksprite ATWIN GSM Shield module compatible for Arduino Nodemcu microcontroller is used to realize the Communication subsystem. The GSM module requires ATcommand protocol to perform so that it should be described in the Arduino microcontroller program code.

\section{RESULTS AND ANALYSIS}

Tool and system tests were conducted in stages that examine each component/tool, the subsystems, and the overall system.

1) Test on each component / tool function: The test was conducted to avoid errors resulted from one of the components/tools which is not functioning by using digital multi-meter measurement tool and software for each device.

a) Test on voltage source: To determine the voltage capacity from the voltage source whether it could provide the voltage needed by the system, the voltage source test was conducted. The voltage source was connected to the voltage regulator circuit consisting of several components of the regulators such as IC 7805, IC 7809, and IC 7812 to adjust the requirements of the voltage on the system. 
The test generated the error values calculated by the following formula: Value |

Error $=\mid$ Ideal Voltage Value - Average Measured Voltage

b) Test on tags and RFID reader: Three units of Radiofrequency identification tags were carried out by using Radiofrequency identification Tester software. The Radio-frequency identification minimum circuit was connected to one unit of portable computer ACER 4752G. It would transmit the data contained in the Radio-frequency identification tag serially to the computer unit via a USB. In the first tag test, the data were obtained in tag 1 number 8802570 . In the second tag test, the data were obtained in tag2 number 8806445 . In the third tag test, the data were obtained in tag 3 number 7706262 .

c) Microcontroller nodemcu test: The test aimed to determine the conditions of Microcontroller nodemcu whether it was in a good condition or not. Test main controller Microcontroller nodemcu was conducted by using software IDE (Integrated Development Environment) 1.0.5 Arduino. The microcontroller fitness could be determined by connecting it to the computer then upload the sample program to the Nodemcu by using the Arduino IDE software.

2) Subsystem test: The test was conducted to ensure that the subsystem was able to perform its function according to the needs of the system. The test was carried out on the detection subsystem, control subsystem and output subsystem, and then whether the output results were in accordance to the system or not was observed.

a) Radio-frequency identification subsystem test: In the subsystems test, an Radio-frequency identification Reader ID12 LA, an Arduino nodemcu microcontroller unit, a series of minimum output systems, and an Arduino IDE 1.0.5 software were used. This test was conducted to identify the ability of Radio-frequency identification subsystem in reading RFID tags, transmitting the ASCII data information to the microcontroller Arduino nodemcu and displaying a series of Arduino IDE 1.0.5 software on the monitor. The Radiofrequency identification test using three card tags is shown in Table I. It can be seen that the Radio-frequency identification tag card has a universal number in the form of a Hexsa number.

3) Test on global positioning system detection subsystem: A CN-06 U-blox global positioning system Receiver, an Arduino Nodemcu microcontroller unit, a U-Center global positioning system Evaluation Software, computers, and an Arduino IDE 1.0.5 software were used in the test. Retrieval global positioning system data namely latitude and longitude data were taken at several points in inside and outside Muhammadiyah University area in Yogyakarta randomly. Global positioning system Detection Subsystem Test Results are presented in Table II. There are three global positioning system testing locations and each location has latitude and longitude data.
4) Action relay subsystem test: The test used a relay activator circuit, a 12 Volt voltage source, a Microcontroller Nodemcu, computers, and an Arduino IDE 1.0.5 software to determine the circuit performance as the switch connects and breaks the relay based on the instructions given by the main control of the Microcontroller. The command was affected by the input received from the computer via serial communication by using a USB. The relay subsystem test result is presented in table 3 . The table shows the relay experimental data using the characters 0 and 1. Character "1" places the relay in connecting position to turn LED lights on, whereas the character " 0 " places the relay in disconnecting position so that the LED light off. When the character 0 was tested, the microcontroller logic was low so that the relay was off, but when the character 1 was tested, the microcontroller logic was high so that the relay was on.

5) Test on GSM communications subsystem: A microcontroller Arduino Nodemcu, SSCOM32E software, Arduino IDE 1.0.5 software, sim900 GPRS/GSM Shield module, a mobile phone, and a computer were used in the test. The test was conducted to ensure that the sim900 GPRS/GSM Shield module was able to realize the communication between the microcontroller Arduino with the mobile phone.

Linksprite sim900 GPRS/GSM Shield is a communication module compatible for microcontroller Arduino nodemcu. The module supports GSM service. sim900 GPRS/GSM Shield supports SMS (Short Message Service) in Text format and PDU (binary). The $900 \mathrm{MHz}$ frequency of Sim900 GPRS/GSM Shield is very supportive to be used in Indonesia. Testing the characters in GPRS/GSM is shown in table 4. It can be seen that the characters AT+CMGS = $\backslash "+6285267897892 \backslash "$ is used for SMS and ATD characters +6285267897892 is used for a call.

6) System test: The test was performed on the operating system and the entire system by combining subsystems into a single integrated system. It was also performed to test the functionality of the system as shown in Fig. 5 and to observe the outputs or results of system operations. The system test is the test conducted after integrating the existing subsystems.

TABLE I. RESULTS OF IDENTIFICATION RFID SUBSYSTEM TEST

\begin{tabular}{|l|l|l|}
\hline No & Tag & Data \\
\hline 1 & Tag 1 & 2C006DF56CD8 \\
\hline 2 & Tag 2 & 6F008654833E \\
\hline 3 & Tag 3 & 6 F0086548439 \\
\hline
\end{tabular}

TABLE II. TEST RESUlts OF GPS DETECTION SUbSYSTEM

\begin{tabular}{|c|c|c|c|}
\hline No & Location & Data LATITUDE & Data LATITUDE \\
\hline 1 & Location 1 & -7.809535 & 110.320494 \\
\hline 2 & Location 2 & -7.808446 & 110.321219 \\
\hline 3 & Location 3 & -7.811648 & 110.321586 \\
\hline
\end{tabular}


TABLE III. RESULT OF RELAYACTION SUBSYSTEM TEST

\begin{tabular}{|l|l|l|l|}
\hline No & Character & Microcontroller & condition Relay \\
\hline 1 & 0 & Low & Off \\
\hline 2 & 1 & High & On \\
\hline 3 & 0 & Low & Off \\
\hline
\end{tabular}

TABLE IV. GSM COMMUNICATION TEST RESULTS

\begin{tabular}{|l|l|l|}
\hline No & Character & Microcontroller \\
\hline 1 & O & AT + CMGS $=$ \"+6285267897892।" \\
\hline 2 & I & ATD+6285267897892; \\
\hline
\end{tabular}

Table $\mathrm{V}$ shows a time delay for some of the actions given as a response to some of the condition listed in the table. The table shows that the system performs time delay to turn the relay and LCD on and to send SMS.

Preparation Time delay is a time delay that occurs when a new system is turned on. Delay time relay On is a time delay needed after the input conditions of RFID tag is correct and the key which was switched on to activate the relay. The delay time relay Off 1 was the delay needed after that was switched off to inactivate the relay. The delay time relay Off 2 was the delay needed after the input conditions of GSM character input are fulfilled to activate the relay. The system encountered a delay time of preparation by an average of 5.6 seconds after getting power from the voltage source. The system was able to response to the input conditions with the average time delay of 1.6 seconds.

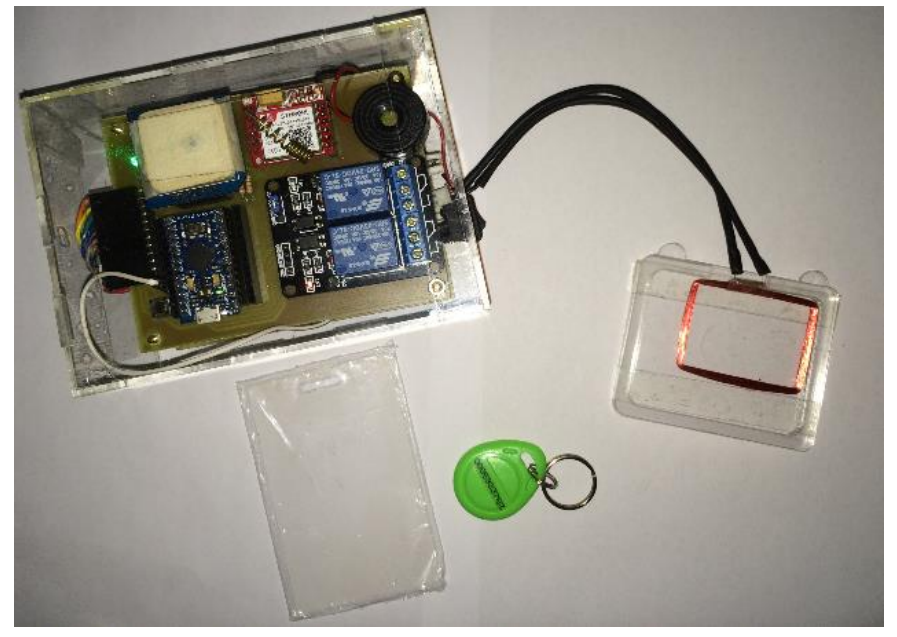

Fig. 5. System Realization.

TABLE V. System Test Results

\begin{tabular}{|l|l|l|l|l|}
\hline No & Input Media & Output Media & Output & $\begin{array}{l}\text { Time } \\
\text { delay }\end{array}$ \\
\hline 1 & Subsystem RFID & Subsystem Relay & Relay On & $1,2 \mathrm{~ms}$ \\
\hline 2 & Subsystem GPS & $\begin{array}{l}\text { Subsystem } \\
\text { Microcontroller }\end{array}$ & LCD & $1.6 \mathrm{~ms}$ \\
\hline 3 & Subsystem GSM & $\begin{array}{l}\text { Subsystem } \\
\text { Microcontroller }\end{array}$ & SMS & $2.1 \mathrm{~ms}$ \\
\hline
\end{tabular}

latitude $=-\underline{5.361485}$

longitude $=\underline{105.242614}$

Posisi = Laboratorium

Terpadu Teknik Elektro

Wilayah = Universitas

Fig. 6. SMS System Display on Mobile Phones of Vehicle users.

Table $\mathrm{V}$ shows the various input conditions and forms of action provided by the system. Microcontroller Arduino nodemcu provides the actions by connecting the Relay when the data of RFID tag are appropriate and making a phone call to the phone number registered. When the RFID tag data are corresponding, the vehicle is on. the microcontroller also sends information about the location of the vehicle in the form of a short message to the phone number listed as shown in Fig. 6.

\section{DISCUSSION}

Based on the results of the tests that have been carried out on the systems for identification, detection, actions and communication, the results obtained is in accordance with the provisions of the system functionality. The system is able to distinguish RFID tags objects as the access key to the engine from ASCII data stored in the tag and then takes action by connecting a series of vehicle engines. The system is able to distinguish the incoming SMS characters through Linksprite GSM Shield module and then takes action by replying to SMS providing vehicle position information so that the system is able to communicate with the mobile devices of the owner.

The identification, detection, and communication on the systems needs a series of communication process using the main data processor Microcontroller Arduino Nodemcu. The main data processor Microcontroller Arduino Nodemcu has a pair of pins of serial communication of data transmitter (Tx), and data receiver $(\mathrm{Rx})$ in which it is capable only of communicating with the process of receiving data at one time. The system which has three serial communication process, namely, (RFID identification, detection of global positioning system and GSM communications) is needed. The need is fulfilled by using two pairs of fake pin serial addition utilizing the program code libraries "SoftwareSerial" and "AltSoftSerial". The Baud Rate of 9600 is used for the pin. Basically, fake pin serials have the same principle as the original serial pins discovered in the Arduino Nodemcu, but they work interchangeably in a very short time having the risk of accumulated delay time.

The results of the tests showed a time delay experienced by the system work is caused by several factors; one of those is the influence of environmental conditions such as building construction and weather capable of disrupting the state of signals for data communications and the effect of time delay program. The performance of the global positioning system receiver to receive data from satellites and transmit it to the microcontroller Arduino Nodemcu is deeply affected by the buildings construction that block the radio waves transmission between the global positioning system receiver and the satellites. The weather affects the performance of GSM Shield 
in receiving the data in the form of a short message or a call during a loss of signal. The time delay in the program uploaded to the microcontroller is the major delay of the time delay value of the system.

\section{CONCLUSION}

Double security systems have been realized interactively on two-wheel motor vehicles and it is capable of distinguishing the RFID tag based on the ASCII data saved to turn on the vehicle and providing information about the vehicle location. The system is equipped with an emergency safety feature by utilizing GSM communication to turn off the machine when it is stolen. The accuracy of the information is affected by the time delay of the system and environmental conditions. To make the system effective, the time delay of the entire system can be tolerated with the average value of the preparation delay time of 5.6 seconds and average delay time of $1.6 \mathrm{~s}$. That the voltage source system is in a good condition is shown by the error acquisition of $4,067 \%$ on the source system voltage.

\section{REFERENCES}

[1] M. A. M. Nasir and W. Mansor, "GSM based motorcycle security system," in 2011 IEEE Control and System Graduate Research Colloquium, 2011, pp. 129-134.

[2] V. Tang, Y. Zheng, and J. Cao, "An Intelligent Car Park Management System based on Wireless Sensor Networks," in 2006 First International Symposium on Pervasive Computing and Applications, 2006, pp. 65-70.

[3] V. K. Sehgal, M. Singhal, B. Mangla, S. Singh, and S. Kulshrestha, "An embedded interface for GSM based car security system," Proc. - 2012 4th Int. Conf. Comput. Intell. Commun. Syst. Networks, CICSyN 2012, pp. 9-13, 2012.

[4] Z. Yihua, "VIP customer segmentation based on data mining in mobilecommunications industry," in 2010 5th International Conference on Computer Science \& Education, 2010, pp. 156-159.

[5] Rui Chen, "Research on security authentication of hierarchy distributed Wireless Sensor Network," in 2010 The 2nd International Conference on Computer and Automation Engineering (ICCAE), 2010, vol. 3, pp. 275278.

[6] S. A. Hameed, S. Abdulla, M. Ershad, F. Zahudi, and A. Hassan, "New automobile monitoring and tracking model: Facilitate model with handhelds," in 2011 4th International Conference on Mechatronics (ICOM), 2011, no. May, pp. 1-5.

[7] B. Gurung, P. W. C. Prasad, A. Alsadoon, and A. Elchouemi, "Enhanced Virtual Password Authentication Scheme Resistant to Shoulder Surfing," in 2015 Second International Conference on Soft Computing and Machine Intelligence (ISCMI), 2015, pp. 134-139.

[8] T. R. Borah, K. K. Sarma, and P. H. Talukdar, "Retina recognition system using adaptive neuro fuzzy inference system," in 2015 International Conference on Computer, Communication and Control (IC4), 2015, pp. 1-6.

[9] Bhagwat Keshav S. and Patil Pradeep M., "Face authentication using fusion of 3D Shape and Texture," in 2014 International Conference on
Advances in Engineering \& Technology Research (ICAETR - 2014), 2014, pp. 1-6.

[10] Yi-Qi Gui and Jie Zhang, "A new authentication RFID protocol with ownership transfer," in 2013 International Conference on ICT Convergence (ICTC), 2013, pp. 359-364.

[11] I. Iswanto, A. Ataka, R. Inovan, O. Wahyunggoro, and A. Imam Cahyadi, "Disturbance Rejection for Quadrotor Attitude Control Based on PD and Fuzzy Logic Algorithm," Int. Rev. Autom. Control, vol. 9, no. 6 , p. 405, 2016.

[12] R. Mubarok, D. V. Firmansyah, D. Haryanto, N. P. Apriyanto, U. Mahmudah, and I. Iswanto, "Motorcycle-Security using Position Searching Algorithm Based on Hybrid Fuzzy-Dijkstra," Indones. J. Electr. Eng. Comput. Sci., vol. 3, no. 2, pp. 468-474, 2016.

[13] I. Iswanto, O. Wahyunggoro, and A. I. Cahyadi, "Hover Position of Quadrotor Based on PD-like Fuzzy Linear Programming,” Int. J. Electr. Comput. Eng., vol. 6, no. 5, pp. 2251-2261, 2016.

[14] Iswanto, O. Wahyunggoro, and A. I. Cahyadi, "Trajectory and altitude controls for autonomous hover of a quadrotor based on fuzzy algorithm," in 2016 8th International Conference on Information Technology and Electrical Engineering (ICITEE), 2016, pp. 1-6.

[15] N. M. Raharja, E. Firmansyah, and A. I. Cahyadi, "Hovering Control of Quadrotor Based on Fuzzy Logic," Int. J. Power Electron. Drive Syst., vol. 8, no. 1, pp. 492-504, 2017.

[16] T. P. Tunggal, A. Supriyanto, N. M. Z. R, I. Faishal, I. Pambudi, and Iswanto, "Pursuit Algorithm for Robot Trash Can Based on Fuzzy-Cell Decomposition,” Int. J. Electr. Comput. Eng., vol. 6, no. 6, pp. 28632869, 2016.

[17] Iswanto, O. Wahyunggoro, and A. I. Cahyadi, "Path planning of decentralized multi-quadrotor based on fuzzy-cell decomposition algorithm," in 7TH INTERNATIONAL CONFERENCE ON MECHANICAL AND MANUFACTURING ENGINEERING: Proceedings of the 7th International Conference on Mechanical and Manufacturing Engineering, Sustainable Energy Towards Global Synergy, 2017, pp. 0200601-02006010.

[18] Iswanto, O. Wahyunggoro, and A. I. Cahyadi, "Trajectory and Altitude Controls For Autonomous Hover of a Quadrotor Based on Fuzzy Algorithm," in 2016 8th International Conference on Information Technology and Electrical Engineering (ICITEE), 2016, pp. 4-9.

[19] I. Iswanto, O. Wahyunggoro, and A. I. Cahyadi, "3D Object Modeling Using Data Fusion from Laser Sensor on Quadrotor," in ADVANCES OF SCIENCE AND TECHNOLOGY FOR SOCIETY: Proceedings of the 1st International Conference on Science and Technology 2015 (ICST-2015), 2016, pp. 170001-1 - 170001-7.

[20] A. N. N. Chamim, D. Ahmadi, and Iswanto, "Atmega16 Implementation As Indicators Of Maximum Speed,” Int. J. Appl. Eng. Res., vol. 11, no. 15, pp. 8432-8435, 2016.

[21] A. N. N. Chamim, M. H. Gustaman, N. M. Raharja, and Iswanto, "Uninterruptable Power Supply based on Switching Regulator and Modified Sine Wave," Int. J. Electr. Comput. Eng., vol. 7, no. 3, pp. 1161-1170, 2017.

[22] T. P. Tunggal, A. Latif, and Iswanto, "Low-cost portable heart rate monitoring based on photoplethysmography and decision tree," in ADVANCES OF SCIENCE AND TECHNOLOGY FOR SOCIETY: Proceedings of the 1st International Conference on Science and Technology 2015 (ICST-2015), 2016, p. 090004. 